\title{
Make the laboratory work meaningful through Concept maps and V Diagram
}

\author{
Dr. Muhammad Safdar, Dr. Azhar Hussain, Dr. Iqbal Shah, M. H. Tasnim \\ Vice Principal, Islamabad Model College for Boys G-6/2, Islamabad, Pakistan \\ Assistant Professor. Government Ambala Muslim College, Sargodha. \\ Assistant Professor. AIOU, Islamabad. \\ Ph.D Scholor, NUML, Islamabad.
}

\begin{abstract}
This paper describes how these tools (concept map and V diagram) help in improving the standard of learning in the science laboratory. Most of the countries of the third world like Pakistan rely heavily on the parrot fashion learning of facts in science at school level, hence students cannot understand the concepts and unable to solve the everyday life problems. In the light of the work reported here, these instructional tools help in making the learning more meaningful. This study seeks to contribute to this development by considering how the effective use of these tools can be converted into effective and efficient instructional method, looking specifically at physics. It was found that the concept maps and V diagram help to improve the performance of the students and make the learning more meaningful in the physical science laboratories.

Keyword: Concept map; V diagram; Meaningful learning;
\end{abstract}

\section{Introduction}

The two major aims of laboratory work in learning science at school level are: (1) To give practical experience of how scientists use the scientific method to make observations of the natural world, come up with hypotheses and do experiments to obtain evidences to support or disprove these hypotheses; (2) To be proficient at practical work, use of scientific equipment, appropriate mathematics and be able to apply important scientific theories.

Science laboratory is a spacious room where the students in groups carry out their experimental work. It provides many opportunities for students to talk and write about science. With a little thought and planning on the part of the students, its activities can be the basis for building communication and problem solving skills. Kempa (1976), Zaman (1996) and Safdar (2010) have the views that the process of practical work has stages which are widely known as forming a valid and satisfactory framework within which practical skills are to be developed and assessed; (a) Recognition and formulation of the problem. (b) Planning and designing of an investigation in which the student predicts the results. (c) Formulate hypotheses and designs procedures. (d) Carrying out the experiments in which the student makes decisions about investigative techniques and manipulates materials and equipment. (e) Observational and measuring skills. (f) Analysis, application and explanation in which the student processes data, discusses results, explores relationships, and formulates new questions and problems.

In the view of Sarikaya et al. (2004) laboratory practical is an important component of science lessons but students can't integrate with theory. According to Nakhleh (1994), laboratory creates learning environment but the students can't structure information in laboratory environment according to constructivist learning theory. He further goes on to say that in order to structure information, active learning, responsibility and encouragement are important and because of this he drew attention to the importance of $\mathrm{V}$ diagram and concept maps.

The use of concept maps and $\mathrm{V}$ diagram stems from the information processing theory of learning and also includes the idea of meaningful learning presented by Ausubel. According to these theories, knowledge is organized in a propositional network. Each individual's network is unique due to each person's unique experiences. The propositional network is not stable; as new information is learned, the network changes and more linkages are formed between concepts. Safdar (2010) quotes Ausubel, that meaningful learning takes place when new knowledge is linked to what a student already knows. Hence, before planning laboratory experiments, it is important to identify in advance ways to relate new knowledge to some broad concept or generalization already familiar to a student.

To make the learning more meaningful in the laboratories the students must establish relations between theory and practice and the daily life experiences, changing intangible information to tangible. There is a Chinese proverb, "I hear, and I forget; I see, and I remember; I do and, I understand. Learning by doing is only possible by using laboratories effectively in science courses. In Pakistan, at secondary school level the students use practical note books and laboratory manuals and follow the instructions given about the experiments they 
are going to perform. In this process, students repeat the steps, remembering theoretical knowledge, which has been learned in the course.

The importance of previous knowledge in the learning process has been stressed by educationists and psychologists and it has also been the subject to several investigations. Students' preparation before starting practical work should increase the chances of their understanding what they are doing in the lab. This is intended to avoid a 'cook book' or 'recipe following' scenario. (Zaman, 1996, Safdar, 2010)

In the view of Safdar (2010), one of the criticisms of laboratory work is that the emphasis is usually on the methodological aspects of the exercise. Thus, even if the exercise is well designed, and the student produces a set of results or observations, these are not readily related back in a meaningful way to the conceptual framework that underpins the experimental work. There is an instructional device to link concepts and methods to help to overcome the above problem is called V mapping. Tatar, Korkmaz \& Ören, (2007), states that Vee diagramming is one of the ways to make the laboratories inquiry based learning environment.

Figure 1 Diagram of V map, showing main elements

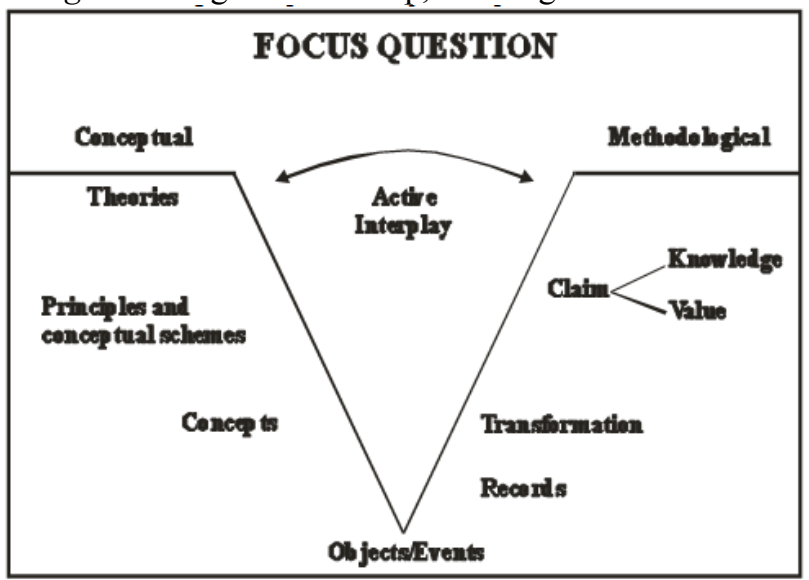

Source: Novak, J.D. (1979, p.484)

At the base of the $\mathrm{V}$ are the events or results that occur as an outcome of some experimental activity. On the left hand side are the theoretical aspects of the work, increasing in generality from the bottom of the $\mathrm{V}$, where specific concepts are cited, to general theoretical schemes at the top. The right hand side is concerned with the methods used to generate knowledge, again arranged in hierarchical order from records taken of the events to generalized knowledge claims. Both sides actively interact with each other through the use of the focus question(s) that directly relates to events and/or objects. The conceptual side includes theory, principles, and concepts all of which are related to each other and to the events and/or objects. On the methodological side of the Vee, records of these events/objects are transformed into graphs, charts, tables, transcriptions of audio or videotapes, and so forth and become the basis for making knowledge and value claims. The major purpose of the $\mathrm{V}$ is to help students understand the function of laboratory work in science; it is particularly useful if constructed as a pre-laboratory activity.

The teacher might construct a V map in a tutorial session, building up the Connections between theory and method by starting with the discussion of the event being observed. This leads to a discussion of what records might be taken and what concepts were used to guide observation of these particular events, or take these particular records. An alternative approach is to provide some aspects of the V and then expect students to complete the maps as an individual exercise.

$\mathrm{V}$ maps can also be included in laboratory manuals. He further goes on to say that the major value of $\mathrm{V}$ map is that students can be developed as an active consideration of all the facets of experimental science, and not just the methodological features. The $\mathrm{V}$ encourages students to think as scientists before they enter the laboratory rather than behave as recipe followers.

Literature reviews reflects that V-diagrams and concept maps as a teaching strategy are widely used in science, especially chemistry and biology courses (Nakleh, 1994; Sarıkaya et al., 2004), while this strategy is not used often in physics courses at school level. From this point of view we hope this research will contribute to the literature.

Safdar (2010), states that Concept maps are useful tools to help students learn about their knowledge structure and the process of knowledge construction. In this way, concept maps also help the student learn, how to learn (meta-learning). Concept mapping requires the learner to operate at all six levels; knowledge, comprehension, application, analysis, evaluation, and creation (synthesis) of Bloom's educational objectives of 
cognitive domain. The need for instructional tools, such as the Vee diagram, to enhance meaningful learning has been stressed by Novak (1977, 1990), and Marino C. Alvarez, Victoria J. Risko (2007).

\section{Methodology}

The purpose of this work was to determine if Vee diagrams could be taught, understood, and used meaningfully to help $9^{\text {th }}$ grade students learn concepts in a science experiment in the physics laboratory. The focus question was "Can $9^{\text {th }}$ graders learn science concepts meaningfully in the physical science laboratory through the use of a Vee diagram and concept map?"

The researcher selected a group of thirty students and divided into two matched groups (experimental $\&$ control) of fifteen each on the bases of the marks achieved by the sample students in the first term exam in the subject of physics. The experimental group was exposed of treatment that is used the Vee diagram as a learning tool. To measure the pre-knowledge of the students, an objective type test (consisted of MCQs) was used to assess the degree of prior knowledge with the concept to be studied. Most of the students were unable to produce an accurate account of the designated concept "The Simple Harmonic Motion".

The researcher being an experienced person (having knowledge and skills) and used these tools (concept maps and Vee diagrams) to make the learning more meaningful. The researcher used the following procedure while introducing the Vee Diagram.

First of all the researcher explained the students how to construct the concept map. Once students are familiar with using concept maps, they are shown how concept maps supply most of the information on the "left side" of the Vee. The main purpose of introducing the concept mapping procedure was that the experimental group familiarizes with two elements of the Vee: concepts, and events and/or objects.

Figure 1

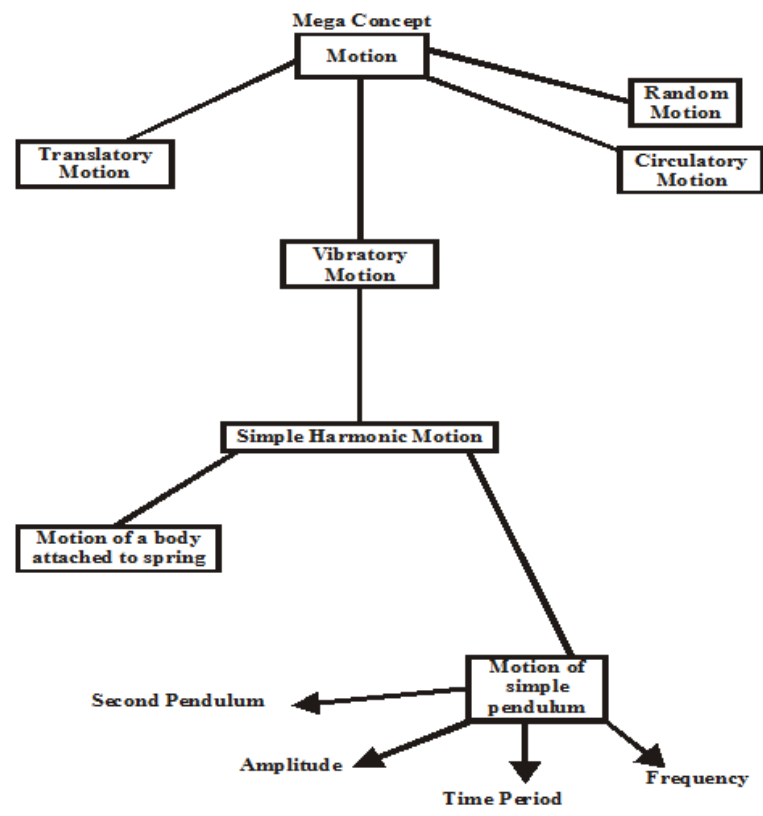

In the second step teacher provided the experimental group, a lecture /demonstration of one hour highlighting the essential work to be done in the laboratory by explaining and defining the terms, concepts, events and objects, how to record facts and their presentation, and focus questions. During demonstration the researcher explained how records are used to observe events or objects. Based on these observations of events or objects, records are made (e.g. measurements of time, length, mass, diameter, temperature, etc.) which are then transformed into some useful information.

This information is organized and put into observation table, or presented in the form of graph, chart, diagram, etc. The data was then transformed into useful information to answer the focus question(s). The Students verify and check from the observation table and the information gain (that is the knowledge claims in accordance with their prior knowledge about the concepts and principles already known to them or is there any misconception).

Principles and theories follow knowledge claims when introducing the Vee diagram. Principles tell how events or objects appear to behave. For example, in the experiment, "Motion of the Simple Pendulum" the principles /laws derived from the outcome are: "Law of mass of simple pendulum, Law of isochronisms of 
simple pendulum, Law of length of simple pendulum." Theories show why events or objects appear to behave as they do.

After three days the experimental group (15 science students) was engaged in the experimental work in the physical science laboratory by using concept map and Vee diagram for the period of two hours. On the same day the control group was also engaged in the laboratory activities to perform the experiment; "Motion of the Simple Pendulum" by using laboratory manual/practical note-book (as recipe follower).

After completing the practical work, both the groups were exposed of a small but comprehensive postlab. The purpose of introducing this post-lab work was to relate the theory with the practical work (i.e. to verify laws, principles.) and to find the effects of Vee diagramming and concept map on the learning of the students. Post-lab problems were chosen from the physics Text Book for secondary classes and from everyday life to develop students interest in physics, to engage them more and relate the subject to their own experiences. This can help them to develop a better understanding of the experiment.

\section{Post-Lab Motion Of Simple Pendulum}

The following questions will help you to consolidate the work you did in the lab and help you to make the learning more meaningful.

(A) Read the statements carefully and tick ( ) the coyrect answer.
1. The time period of second pendulum is:
(a) $\quad 0.02 \mathrm{sec}$.
(b) $\quad 0.20 \mathrm{sec}$
(c) $\quad 2.00 \mathrm{sec}$
(d) $\quad 2.20 \mathrm{sec}$

2. A simple pendulum is made of plastic ball (as a bob) filled with water and have a hole in it. During the oscillation, due to the flow of water, its mass decreases. What will be the effect on the time period? (Law of mass of simple pendulum)
(a) It will increase
(b) It will decrease
(c) It will remain same
(d) none of $\mathrm{a}, \mathrm{b}, \mathrm{c}$.

3. If the bob of the pendulum of given length is replaced by another bob of different material what will be the effect on the time period?
(a) It will increase
(b) It will decrease
(c) It will remain same
(d) none of $a, b, c$.

4. If the oscillation of a simple pendulum of a given length became small. What will be the effect of smaller oscillations on the time period? (Law of isochronisms of simple pendulum)
(a) It will increase
(b) It will decrease
(c) It will remain same
(d) none of a, b, c.

5. If we decrease the length of the simple pendulum. What will be the effect of length on the time period? (Law of length of simple pendulum)
(a) It will increase
(c) It will remain the same
(b) It will decrease
none of $\mathrm{a}, \mathrm{b}, \mathrm{c}$.

(B) Write the short answers (on the space given below) of the following questions.

1. What will you prefer; a fine wire or a fine thread of making a simple pendulum?

2. By using formula ( $g=4 \pi^{2} \times l / \mathrm{T}^{2}$ ) Find the value of $\mathrm{g}$ by taking the mean length (I) and the time period (T) from your experiment you have just done. Is it $981 \mathrm{~cm} / \mathrm{s}^{2}$ ?

\section{Hypothesis of the study}

There is no significant difference between the achievement scores of the students in the subject of Physics (Practical) with and without Vee diagram.

\section{Analysis of Data}

The marks achieved by the students in the post laboratory activity are presented in table 2 below. 
Table 2

$9^{\text {th }}$ Grade Students' "Mean Scores" in Physics Practical (the motion of simple pendulum)

\begin{tabular}{|c|c|c|c|c|}
\hline $\begin{array}{c}\text { (Experimental } \\
\text { group) Students } \\
\text { With Vee diagram }\end{array}$ & $\begin{array}{c}\text { (Control group) Students } \\
\text { Without Vee diagram } \\
\mathrm{X}_{1}\end{array}$ & $\begin{array}{c}\text { Standard } \\
\text { Deviation } \\
\mathrm{S}_{1}\end{array}$ & $\begin{array}{c}\text { Standard } \\
\text { Deviation } \\
\mathrm{S}_{2}\end{array}$ & $\begin{array}{c}\mathrm{t} \text {-Test a 5\% level of } \\
\text { significance }\end{array}$ \\
\hline 15.9 & 13.6 & 3.97 & 2.52 & $\begin{array}{l}\mathrm{t}_{\text {cal }}=3.03 \\
\mathrm{t}_{\text {tab }}=1.98 \\
\mathrm{df}=28\end{array}$ \\
\hline
\end{tabular}

The t-test was applied to evaluate whether there was any significant difference between the achievement scores of students in the post lab activities with Vee diagram and Without Vee diagram. The result indicated that the mean concern for students with Vee $(\underline{\mathrm{M}}=15.9, \underline{\mathrm{SD}}=3.97)$ was significantly greater than the mean concern for Students without Vee diagram $(\underline{\mathrm{M}}=13.6, \underline{\mathrm{SD}}=2.52), \underline{\mathrm{t}}(28)=3.03$. As our $\mathrm{t}$-calculated value is greater than the $\mathrm{t}$-tabulated value, therefore the above stated null hypothesis that "there is no significant difference between the achievement scores of the students in the subject of Physics (Practical) with and without Vee diagram was rejected".

\section{Discussion and conclusions}

The findings of this study are consistent with the findings of the research studies conducted by Marino C. Alvarez, Nashville, Tennessee, and Victoria J. Risko (2007), Novak, J.D., Gowin, D.B., \& Johansen, G.T. (1983). Hence this study helps to improve the students' understanding of concepts in the physical science laboratories and make the learning more meaningful to the secondary school science students.

The results of this study are also consistency with the findings of the previous studies. Özgül Keleş and Sibel Özsoy (2009), found Vee diagramming more effective than traditional laboratory. Ramahlape (2004) stated that learners find Vee diagram informative, useful and facilitative to their conceptual understanding. Besides, Nakiboğlu \& Meriç (2000) also reported that Vee diagram is helpful for conceptual understanding.

In this study, Vee diagram and concept map were practical tools in learning about the structure of knowledge and the processes of knowledge production. They facilitate $9^{\text {th }}$ grade science students to observe a piece of knowledge and come away with a deeper understanding of how knowledge is constructed by showing concept map. These students were able to learn concepts associated with the science experiment.

Students of the experimental group, during the pre-lab lecture were free to express their thoughts about the concepts, make predictions, and raise questions in meaningful contexts with each other and with the teacher. They were able to make connections, structure their knowledge, and create their own meaning (i.e., to see how the elements on the Vee related to the focus question and events that they formulated). Vees served as an evaluation instrument for both the teacher and the student in determining how well ideas were represented among the component parts of the Vee diagram.

The Researcher and the students were able to resolve doubts / confusion /misunderstanding and make the event a meaningful learning experience. Students recognized that the information given in the physics textbook for class nine could be used to create new meaning by recombining facts into ideas.

Vee diagram and concept map have positive as well as negative aspects. Positive aspects of Vee diagram is to make students think higher-order thinking skills (HOTS) along with lower order thinking skill (LOTS), to follow every steps by students and teachers easily, to assess objectively and easily, to determine research question, , to provide meaningful learning, to enhance all the domains of Blooms Taxonomy (cognitive affective, and psychomotor). Negative aspects are, if the students are not given information about how to use Vee diagram and how to develop concept maps, they may be bored during practical work. Secondly, it needs a lot of expertise on the part of the teacher, and also time consuming.

\section{References}

[1]. Alvarez, M.C. (1987). The use of knowledge Vee diagrams as an aid to reading comprehension and problem solving. In D. Lumpkin, M. Harshbarger, \& P. Ransom (Eds.), American Reading Forum. vol. 7, 131-140.

[2]. Ausubel, D P. (1966). Meaningful Reception Learning and Acquisition of Concepts in Analysis of Concept Learning. New York: Academic Press.

[3]. Ausubel, D. P. (1963). The Psychology of Meaningful Verbal Learning. New York: Grane and Stratton.

[4]. Bruner, J. S., Goodnow, J. J., and Austin, G. A. (1956). A study of thinking. New York: John Wiley.

[5]. Cross, A. (1992). Pictorial concept maps-putting us in the picture. Primary Science Review, 21, 26-28.

[6]. Driver, R. (1983). The pupil as scientist. Milton Keynes: U.K opens University Press.

[7]. Ebenezer, J. V. \& Connor, S. (1998). Learning to teach science: A model for the $21^{\text {st }}$ Century. London: Prentice-Hall International (UK).

[8]. Johnstone, A. H. (1993). The development of chemistry teaching; a changing response to a changing demand. Journal of Chemistry Education, 70(9),701-05.

[9]. Kempa, R.F. (1976). Science Education Research: Some Thought and Observation" Studies in Science Education. 1976.

[10]. Kilshaw, M. (1990). Using concept maps. Primary Science Review. 12, 34-36. 
[11]. Lambiotte and Dansereau (1991). Concept Mapping: a learning theory-based instructional tool: specific uses of concept mapping in science education, lancraftt@email.spic.cc.fl.us (June 08, 1996)

[12]. Marino C. Alvarez, Nashville, Tennessee, Victoria J. Risko The Use Of Vee Diagrams With Third Graders As A Metacognitive Tool For earning Science Concepts

[13]. Nakhleh, M.B. (1994). Chemical Education Research in the Laboratory Environment: How Can Research Uncover What Students are Learning? Journal of Chemical Education, 71(3), 201-205.

[14]. Novak, J. D. \& Gowin, D. B. (1984). Learning how to learn. Cambridge: Cambridge University Press.

[15]. Novak, J. D. (1990). Concept maps and Vee diagrams: Two Metacognitive Tools to Facilitate Meaningful Learning. Instructional Science, 19, 29-52.

[16]. Novak, J. D. (1991). Clarify with concept maps. The science teacher. 45- 49

[17]. Novak, J.D. (1990). Concept maps and Vee diagrams: Two metacognitive tools to facilitate meaningful learning. Instructional Science, 19, 29-52.

[18]. Novak, J.D., Gowin, D.B., \& Johansen, G.T. (1983). The use of concept mapping and knowledge Vee mapping with junior high school science students. Science Education, 67, 625- 645

[19]. Osborne, C. (1986). International Year Book of Educational and Instructional Technology. Kogan Page / eichols.

[20]. Pines, A. L. (1985). Towards a taxonomy of conceptual relations and the implications for the evaluation of cognitive structures. In L.H.T.West \& A.L. Pines (Eds.), cognitive structure and conceptual change. Orlando, FL: Academic Press. 101-116

[21]. Safdar, M. (2010). A comparative study of Ausubelian and Traditional methods of teaching physics at secondary school level in Pakistan. Unpublished Ph.D thesis. Islamabad. National University of Modern Languages, Islamabad. pp. 66-70

[22]. Sarıkaya, R., Selvi, M., Selvi, M. and Yakışan, M. (2004). V-Diyagramlarının Hayvan Fizyolojisi Laboratuarı Konularını Öğrenme Başarısı Üzerine Etkisi. Gazi Eğitim Fakültesi Dergisi, 24(3), 341-347.

[23]. Tatar, N., Korkmaz, H., Şaşmaz Ören, F. (2007). Araştırmaya Dayalı Fen Laboratuarlarında Bilimsel Süreç Becerilerini Geliştirmede Etkili Araçlar: Vee ve I Diyagramları. Elementary Education Online, 6(1), 76-92. 